ARTIGO

\title{
Remuneração docente: efeitos do plano de cargos, carreira e remuneração em contexto municipal*
}

Maria Dilnéia Espíndola Fernandes a Solange Jarcem Fernandes ${ }^{b}$ Viviane Gregorio de Campo ${ }^{c}$

\section{Resumo}

O trabalho objetivou, por meio de estudo de caso, verificar o efeito produzido pelos Planos de Cargos, Carreira e Remuneração (PCCR), implantados no município de Campo Grande, no período de 1996 a 2016, em termos de remuneração salarial para um professor, ao longo de 20 anos de carreira. O exame do movimento da remuneração do professor foi feito pela análise dos seus holerites, cotejados aos PCCR e ao salário mínimo. Constatou-se que houve um efeito positivo na remuneração do professor com a obrigatoriedade dos PCCR municipais e que a titulação e o tempo de trabalho foram importantes no contexto de valorização. Permaneceu, contudo, em devir histórico no município, o pagamento integral do Piso Salarial Profissional Nacional (PSPN), que também deveria estar garantido por intermédio do PCCR.

Palavras-chave: Política Educacional. PCCR. Remuneração do Professor. Valorização do Professor.

\footnotetext{
* O trabalho teve apoio financeiro da Coordenação de Aperfeiçoamento de Pessoal de Nível Superior (Capes) e do Conselho Nacional de Desenvolvimento Científico e Tecnológico (CNPq). Os autores agradecem à editora Érika Dias por comentários e sugestões ao longo do processo avaliativo.

a Universidade Federal de Mato Grosso do Sul, Campo Grande, MS, Brasil.

b Universidade Federal de Mato Grosso do Sul, Campo Grande, MS, Brasil.

c Secretaria Municipal de Educação, Campo Grande, MS, Brasil.
} 


\section{Introdução}

O trabalho aborda a remuneração salarial de um professor $^{1}$ da educação básica da rede municipal de ensino de Campo Grande, capital do estado de Mato Grosso do Sul, cotejando seus Demonstrativos de Pagamento (holerites) com os Planos de Cargos, Carreira e Remuneração (PCCR), no período de 1996 a 2016. Com vistas a verificar se, no período em tela, os PCCR em vigência promoveram a valorização do professor em termos remuneratórios, compararam-se os vencimentos base e a remuneração com o salário mínimo.

O objetivo do estudo foi averiguar o efeito ${ }^{2}$ da política educacional elaborada pelo governo central, na interseção com a política educacional local, nas condições materiais de existência do professor da educação básica de uma rede municipal de ensino. Porque, certamente, "o grau de descentralização do sistema educacional brasileiro exige que a avaliação de efetividade da política educacional incorpore a sua dinâmica municipal" (GOUVEIA, 2009, p. 450).

Por tudo isso, a decisão metodológica de ser um professor, para tal investigação, justifica-se também por duas razões: primeiramente, remuneração é diferente de salário. Em segundo lugar, as fontes que definem os termos salário e remuneração de professores são diferentes, dada a peculiaridade da construção da carreira docente, que se expressa nos múltiplos PCCR.

Assim, os salários do conjunto de professores de uma rede de ensino podem ser calculados por meio dos resultados das negociações entre administrações públicas estaduais e municipais e representações sindicais de professores e/ ou trabalhadores em educação, ou mesmo quando não há negociações entre as partes, ou, ainda, quando a negociação interrompe-se e medidas são tomadas unilateralmente, por parte das administrações, já que tais decisões, via de regra, são publicadas em Diários Oficiais ou nas esferas informativas/comunicativas de organização docente. Já a remuneração é a soma entre o salário e os direitos advindos da carreira (CAMARGO et al., 2009), por mês trabalhado. As fontes que a elucidam remetem ao controle social democrático do Estado.

\footnotetext{
O professor em questão tinha 46 anos em 2016. Adentrou à carreira docente municipal por meio de concurso público em 1996, com formação em nível médio. Permaneceu nesse nível de carreira até 2004, quando, por meio de titulação (formação em nível superior), ascendeu na carreira para a Referência/Classe $\mathrm{PH} 2 / \mathrm{C}$. Em 2016, este professor havia galgado a Referência/Classe na carreira PH3/E, com a titularidade em PósGraduação em Especialização latu sensu e contava com 20 anos de trabalho no magistério municipal, de acordo com Decreto no 10.343/2008, que atualizou o PCCR (CAMPO GRANDE, 2008).

2 O procedimento metodológico para verificar se o efeito da política educacional em interseção federativa na remuneração do professor em questão pode ser entendido como o acompanhamento de sua remuneração durante o período da sua carreira. Assim, não se tem a pretensão de generalizar possíveis resultados do caso em verificação. Apenas o seu acompanhamento.
} 
Portanto, este texto considera a remuneração como o total da retribuição pecuniária mensal recebida pelo membro do magistério, no exercício do cargo, da qual fazem parte o vencimento base, as vantagens permanentes obtidas por meio das promoções por tempo de serviço e nível de escolarização e os elementos da remuneração denominados gratificações, auxílio-transporte, auxílio de difícil acesso, vantagens pecuniárias pessoais e funcionais, entre outros (CAMPO GRANDE, 1998a).

O trabalho está organizado da seguinte forma: a primeira seção trata do escopo jurídico-legal no período de 1996 a 2016, promovido pela União em interseção com o município de Campo Grande, com vistas à valorização do professor, por meio da remuneração; a seção seguinte aborda o caso da remuneração do professor da rede municipal de ensino de Campo Grande; por último, tecem-se as considerações finais sobre carreira e remuneração.

\section{O escopo jurídico-legal de 1996 a 2016: remuneração e valorização do professor na interseção das políticas educacionais}

Ao disciplinar os dispositivos constitucionais para a valorização profissional dos professores da educação básica, a Lei nº 9.394/1996 (BRASIL, 1996a) delegou-os para os múltiplos sistemas de ensino já existentes, que também estavam sendo objetos de disciplinamento dessa mesma Lei. Diante disso, a valorização profissional dos professores de educação básica, de forma descentralizada, ficou sob a responsabilidade de cada ente federativo, mediante a aprovação local de PCCR.

Paradoxalmente, quatro dias depois da aprovação da Lei ${ }^{\circ}$ 9.394/1996, foi aprovada a Lei $\mathrm{n}^{\circ} 9.424 / 1996$, que regulamentou a Emenda Constitucional $\mathrm{n}^{\circ}$ 14/1996 (BRASIL, 1996a, 1996b, 1996c), que implantou o Fundo de Manutenção e Desenvolvimento do Ensino Fundamental e de Valorização dos Profissionais do Magistério (Fundef). O paradoxo aqui foi que, enquanto a Lei no 9.394/1996 remeteu a valorização dos profissionais da educação básica aos sistemas de ensino, a Lei $n^{\circ}$ 9.424/1996 instituiu reserva orçamentária de, no mínimo, 60\% dos recursos do fundo para o pagamento de salários; também colocou, pela primeira vez na história, induzido pela União, a obrigatoriedade de os entes federativos aprovarem os PCRR para os membros do magistério (BRASIL, 1996a, 1996b). A aprovação do Fundef rompeu com o acordo que havia sido produzido entre a Confederação Nacional dos Trabalhadores em Educação (CNTE) e a gestão do Presidente Itamar Franco, quanto ao piso salarial nacional em 1994 
(FERNANDES; RODRIGUEZ, 2011). Ainda, segundo as autoras, talvez por isso mesmo, a transferência para o futuro da valorização docente por meio de um piso salarial nacional tenha causado dúvidas entre muitas prefeituras, que confundiram a implantação do valor do custo/aluno/ano/mínimo do Fundef por um piso salarial mínimo aos professores.

Para responder ao contexto da legislação nacional, o município de Campo Grande aprovou a Lei Complementar nº 19/1998 (CAMPO GRANDE, 1998a), que instituiu o PCRR para os professores da rede municipal de ensino. Assim, o PCCR do município de Campo Grande garantiu aos docentes: uma carreira que se sustentaria na habilitação profissional; ingresso exclusivo por concurso público de provas e títulos; aperfeiçoamento continuado; remuneração conforme a titulação; período reservado a estudos; planejamento e avaliação na carga horária de trabalho; promoção funcional conforme a titulação e avaliação de desempenho. A jornada de trabalho foi instituída em 20 e 40 horas, com sete e 14 horas, respectivamente, para planejamento, e $50 \%$ das horas-atividades cumpridas fora do ambiente escolar (CAMPO GRANDE, 1998a).

A aprovação da Lei $n^{0}$ 11.494/2007 (BRASIL, 2007), que instituiu o Fundo de Manutenção e Desenvolvimento da Educação Básica e de Valorização dos Profissionais da Educação (Fundeb), manteve a subvinculação de $60 \%$ dos seus recursos orçamentários para os salários dos profissionais da educação básica e as exigências de um PCCR em cada ente federativo.

As alterações no PCCR do município foram de adequações para garantir a interseção da política nacional com a local. A indução da União materializou-se no município perante as reformulações que o Decreto Municipal ${ }^{\circ}$ 10.343/2008 (CAMPO GRANDE, 2008a) introduziu no PCCR. Tais alterações expressaramse em carga horária, remuneração e formação docente.

Entretanto, o Fundeb determinou, no artigo 41, o prazo para a aprovação de lei de instituição do Piso Salarial Profissional Nacional (PSPN). Ainda que a Lei do PSPN não tenha sido aprovada no prazo estabelecido pelo Fundeb, que seria até 31 de agosto de 2007, foi aprovada em junho de 2008, pela Lei $\mathrm{n}^{\circ} 11.738$ (BRASIL, 2008a).

A Lei $\mathrm{n}^{\circ}$ 11.738/2008 (BRASIL, 2008a) virou contenda federativa, somente resolvida em 2011, com ganho de causa parcial à União (FERNANDES; RODRIGUEZ, 2011). Enquanto os estados questionavam a União sobre a quebra de autonomia federativa (Id. Ibid), com Ação Direta de Inconstitucionalidade 
(ADIn) sobre a Lei $\mathrm{n}^{\circ}$ 11.738/2008 (BRASIL, 2008a), os municípios, em sua grande maioria, inclusive o de Campo Grande, entraram em compasso de espera para implantar o PSPN. Observou-se, em Campo Grande "que, o professor formado em nível superior, em início de carreira, percebeu um salário de $85 \%$ do valor do PSPN. Nas mesmas condições, o professor portador de especialização obteve um vencimento da ordem de $94 \%$ do valor do PSPN" (FERNANDES et al., 2018, p. 7).

O período seguiu entrecortado pelo processo iniciado em 2007, que consubstanciou um novo patamar de participação da sociedade, com vistas ao alargamento da democracia, que se expressou na condução da política educacional e que fecundou na Conferência Nacional da Educação Básica (CONAE, 2008), tendo como imperativo a construção de um sistema nacional articulado de educação (BRASIL, 2008b). Na sequência, foram realizadas mais duas Conferências Nacionais de Educação, em 2010 e 2014, que objetivaram a construção do novo Plano Nacional de Educação (PNE) (BRASIL, 2010, 2014a). As Conferências em questão tomaram como central, a valorização docente por meios remuneratórios e dedicaram eixos de trabalho, para que tal objetivo fosse inscrito no PNE.

O PNE vindouro chegou, ainda que tardiamente. A aprovação do PNE, que deveria ter sido em 2010, ocorreu somente em 2014, quando, em complexo processo de correlação de forças sociais, aprovou-se a Lei $\mathrm{n}^{\circ}$ 13.005/2014, sancionada sem veto pela Presidente da República (BRASIL, 2014b) ${ }^{3}$.

O PNE 2014-2024 requereu o alinhamento entre os Planos Estaduais e Municipais de Educação. Dispôs, na Meta 17, a valorização dos profissionais da educação básica e reconheceu que ganhavam, à época, 33\% a menos que outros profissionais com o mesmo grau de formação e jornada de trabalho equivalente (BRASIL, 2014b).

Os professores da rede municipal de ensino de Campo Grande, representados pelo Sindicato Campo-Grandense dos Profissionais da Educação Pública (ACP),

\footnotetext{
3 Cumpre esclarecer que o PNE é um dispositivo da Constituição Federal de 1988, instituído pelo artigo $n^{\circ} 214$, com duração decenal. O primeiro deles foi elaborado na administração de Itamar Franco, em 1993. Em 2001, na administração de Fernando Henrique Cardoso, foi aprovado um novo PNE, Lei $n^{\circ} 10.172$ (BRASIL, 2001). Cabe lembrar que naquele Plano de 2001, as metas relativas a ampliação de recursos para promover a ampliação da educação, foram todas vetadas (DOURADO, 2017). Pontua-se que nos anos de 1990, setores da sociedade civil brasileira disputaram abertamente com o governo de Fernando Henrique Cardoso um PNE (VALENTE, 2001). Em 2014 foi aprovado o atual PNE 2014-2024, que, conforme Dourado (2017, p. 176), "a discussão sobre as políticas e gestão da educação, especialmente do PNE entendido como epicentro, expressa uma tessitura sócio-política complexa, que se articula às agendas transnacionais, ao Estado nacional, à relação entre os entes federados, [...], entre outros pontos".
} 
envolveram-se em duas grandes demandas, a saber: a discussão em torno da aprovação do PNE, que resultaria em um novo Plano Municipal de Educação, alinhado ao novo PNE, e a luta local pela aprovação de uma lei que garantisse o pagamento do PSPN.

A aprovação do Plano Municipal de Educação ${ }^{4}$, em alinhamento ao PNE, deu-se em 2015; lá está contida, nas Metas 17 e 18, a valorização dos profissionais do magistério, reportando-se ao pagamento do PSPN (CAMPO GRANDE, 2015, p. 44-45).

Sobre a luta local docente para o pagamento do PSPN, em 2013, foi aprovada a Lei $n^{\circ} 5.189$ que, na revisão geral de remuneração docente, previu o pagamento do PSPN de forma escalonada, quando se chegaria a $100 \%$ do PSPN em 2014 (CAMPO GRANDE, 2013). A luta docente local pelo PSPN no município introduziu uma novidade, ainda em 2012, na Lei $\mathrm{n}^{\circ} 5.060$, que seria o pagamento do PSPN pela jornada de trabalho de 20 horas (CAMPO GRANDE, 2012). Tais legislações, contudo, parecem ter fenecido, em razão do processo de impeachment sofrido pelo chefe do Executivo Municipal (DA MATA, 2014).

Em 2014, com a aprovação da Lei ${ }^{\circ} 5.411$, novamente aventou-se a possibilidade de pagamento do PSPN no município (CAMPO GRANDE, 2014a). Essa lei, tal qual a anterior, estabeleceu o pagamento do PSPN de forma escalonada. Assim, em dezembro de 2017, o vencimento base dos professores da rede municipal de ensino de Campo Grande era de $82,11 \%$ do PSPN nacional (SINDICATO CAMPO-GRANDENSE DOS PROFISSIONAIS DAEDUCAÇÃO PÚBLICA, 2017).

No cenário que se estendeu de 1988 até 2016, em termos de concepção, inscreveram-se processos de valorização dos professores da educação básica do país, ainda que a materialização dos direitos previstos no âmbito da legislação e do planejamento em contexto federativo tenha, muitas vezes, acirrado as contradições postas e resultantes.

Dado o contexto da valorização de professores da educação básica, por meio da legislação e do planejamento educacional, quando a interseção entre as políticas educacionais induz dimensões, como pactos e relações federativas em modelos

4 O PME de Campo Grande 2015-2025, alinhou-se ao PNE 2014-2024, reproduzindo suas metas e estratégias. Certamente, o PME aprovado não conseguiu absorver em seus dispositivos toda a riqueza e contribuição da Conferência Intermunicipal de Educação ocorrida em 2013, em Campo Grande (CAMPO GRANDE, 2018). 
fortemente descentralizados, na próxima sessão discute-se o caso da incidência do PCCR nas condições materiais de existência de um professor da rede municipal de ensino de Campo Grande, no período de 1996 a 2016.

\section{A materialização dos PCCR nas condições materiais de existência de um professor}

Como anunciado na introdução, embora haja fontes para consulta sobre a remuneração de professores da educação básica, ao longo dos anos de 2009 a 2016, tais dados apresentam-se dispersos nas diferentes unidades federativas em razão da descentralização de recursos para manutenção e desenvolvimento do ensino, bem como da política educacional. Ainda que o Estado, em complexa correlação de forças sociais, tenha aprovado leis como as de $\mathrm{n}^{0} 131 / 2009$ e $\mathrm{n}^{\circ}$ 12.527/2011, a primeira a Lei da Transparência e a segunda, a Lei de Acesso à Informação (BRASIL, 2009, 2011), fato é que, em sistemas descentralizados de ensino, com a educação básica sob competências e responsabilidades dos poderes locais (estados e municípios), entre a concepção posta pelas leis federais e a sua materialidade para o manuseio dos dispositivos dessas leis, um grande vácuo pode impor-se, impedindo o acesso no tempo necessário.

No âmbito da pesquisa em questão, o plano metodológico foi alterado diversas vezes, dada a impossibilidade de consultar as folhas de pagamento das secretarias de estados e de municípios no tempo necessário, pois essa foi a fonte principal elencada por tal plano. Muito embora, no plano metodológico original, os demonstrativos de pagamento - holerites - tenham sido listados como uma fonte importante, ao longo da pesquisa descobriu-se que os holerites viabilizam estudos de caso, ou estudos sobre casos. No entanto, sob hipótese alguma essa fonte propicia generalizações, como seria exequível a partir da folha de pagamento de uma rede de ensino.

Ao se considerar o holerite como uma fonte reveladora de remuneração, a hipótese levantada foi de que o documento seria registro fiel dos ganhos ou perdas de direitos impressos durante o percurso da carreira do professor, por meio da vigência do PCCR. Assim, o exercício de pesquisa direcionou-se ao cruzamento entre o tempo profissional do professor, os PCCR em vigência no período do tempo profissional, e a remuneração do professor inscrita em seu holerite durante esse tempo. No caso do professor de Campo Grande os holerites confirmaram a hipótese de fidelidade aos ganhos remuneratórios. 
Tal como na investigação de Valle (1982), o procedimento metodológico delineia "ano a ano a situação salarial [e], caracteriza-se como um estudo de caso, pois utilizamos, como fontes primárias, os contracheques de um mesmo professor" (VALLE, 1982, p. 26).

O estudo de caso sobre a composição remuneratória do professor do município de Campo Grande retrata o cenário de valorização docente por meio da remuneração pós Constituição Federal de 1988. O professor em questão iniciou a carreira no magistério por meio de concurso público na rede municipal de ensino, em 1996, ano da aprovação da Lei de Diretrizes e Bases da Educação Nacional e da instituição do Fundef, que determinou a obrigatoriedade de PCCR para os entes federativos (BRASIL, 1988, 1996a, 1996b). O trabalho do professor principiou, portanto, dois anos antes da implantação do PCCR municipal, que se deu em 1998 (CAMPO GRANDE, 1998a).

O tempo de trabalho do professor foi entrecortado por novas alterações no campo jurídico-legal, com vistas à valorização, por meio da remuneração, que se expressaram na aprovação do Fundeb, do PSPN e do PNE 2014-2024 (BRASIL, 2007, 2008a, 2014b). Em interseção para adequar-se à legislação nacional, o município foi aprovando, também, seu escopo jurídico-legal, no tocante à matéria da valorização docente, pertinente ao período em tela (CAMPO GRANDE, 2008, 2012, 2013, 2014, 2015).

Tal interseção, em contexto de política educacional descentralizada, evidencia que a "discussão gira em torno das estruturas salariais que as carreiras docentes implicam" (MORDUCHOWICZ, 2003, p. 6). Até porque, "um dos conceitos de maior peso sobre os custos educativos é o salarial que (tenta) remunerar a experiência" (MORDUCHOWICZ, 2003, p. 13).

Segundo a análise de Morduchowicz (2003) sobre carreiras, incentivos e estruturas salariais docentes no continente latino-americano, a titulação e a antiguidade são fatores comuns na maioria dos países e contribuem para fomentar a economia de escala, dado o quantitativo de professores necessários a cada sistema de ensino.

Em 2016, último ano de verificação, o professor da rede municipal de ensino de Campo Grande havia completado 20 anos de trabalho, portanto, exercido quatro quintos de sua carreira.

A Tabela 1 mostra o movimento na carreira do professor, que foi-se forjando mediante a interseção da política educacional local com a nacional, por meio da legislação. 
Tabela 1 - Município de Campo Grande: composição da remuneração docente de um professor pelo holerite regulamentado pelo PCCR com jornada de trabalho de 20 horas, em valores correntes, 1996-2016

R\$ 1,00

\begin{tabular}{lcccccc}
\hline Ano & $\begin{array}{c}\text { Referência/ } \\
\text { Classe }\end{array}$ & $\begin{array}{c}\text { Vencimento } \\
\text { base no } \\
\text { cargo }\end{array}$ & $\begin{array}{c}\text { Adicional } \\
\text { tempo de } \\
\text { serviço }\end{array}$ & Gratef & Outros** & $\begin{array}{c}\text { Total de } \\
\text { Remuneração }\end{array}$ \\
\hline & PH1/A & 176,95 & 0 & 0 & 97,96 & 274,91 \\
1998 & $\mathrm{PH} 1 / \mathrm{B}$ & 193,23 & 0 & 62,57 & 117,47 & 373,27 \\
2002 & $\mathrm{PH} 1 / \mathrm{C}$ & 291,72 & 14,59 & 113,35 & 123,99 & 543,65 \\
2004 & $\mathrm{PH} 2 / \mathrm{C}$ & 504,86 & 25,24 & 187,71 & 100,97 & 818,70 \\
2008 & $\mathrm{PH} 3 / \mathrm{D}$ & $1.086,10$ & 108,61 & 0 & 409,92 & $1.604,63$ \\
2014 & $\mathrm{PH} 3 / \mathrm{E}$ & $3.574,39$ & 536,16 & 0 & 153,20 & $4.245,75$ \\
2016 & $\mathrm{PH} 3 / \mathrm{E}$ & $4.005,11$ & 801,02 & 0 & 151,49 & $4.957,62$ \\
\hline
\end{tabular}

Gratef: Gratificação de Valorização do Magistério. ** Gratificações de regência de classe, aulas de recuperação, salário família, abonos, Programa de Formação do Patrimônio do Servidor Público (Pasep), entre outros.

Fonte: Elaboração própria (2018) a partir de demonstrativos de pagamentos (holerites) do professor do mês de outubro dos anos: 1996, 1998c, 2002, 2004, 2008b, 2014b e 2016

Como já anunciado, o professor iniciou sua carreira por concurso público em 1996, com formação em magistério, em nível de ensino médio. Em 1998, com a implantação do PCRR no munícipio, em decorrência do Fundo de Manutenção e Desenvolvimento do Ensino Fundamental e de Valorização do Magistério (Fundef), ele foi reenquadrado na carreira na referência/classe PH1B. Com essa promoção horizontal, o professor teve reajuste de $4 \%$ no vencimento base no cargo. Em 1998, o professor passou a receber a Gratificação de Valorização do Magistério, denominada Gratef ${ }^{5}$ que, mesmo sendo uma gratificação transitória, refletiu positivamente em sua remuneração, pois, em 2004, a Gratef deixou de ser transitória para ser permanente.

Em 2002, o professor foi promovido na carreira e ocupou a referência/classe PH1C. Tal feito significou um reajuste de $10 \%$ na promoção horizontal na carreira. Esses adicionais mais a Gratef fizeram com que a remuneração total registrasse ganhos em relação a 1998. Em 2004, o professor foi promovido para a referência/classe $\mathrm{PH} 2 \mathrm{C}$, em razão de ter concluído curso de graduação. Obteve, com isso, uma promoção vertical de $30 \%$, situação que confirma a valorização docente pela titulação expressa no PCRR municipal. Sob a mesma lógica, em 2008, o professor foi promovido para PH3D na carreira, em decorrência da conclusão de curso de pós-graduação lato sensu, o que implicou aumento de $10 \%$ na promoção vertical e $10 \%$ na promoção horizontal. Mais uma vez, os requisitos principais de valorização docente expressos no PCCR municipal 
foram a titulação e a antiguidade, ou o tempo de trabalho. Em 2014, o professor ascendeu à referência/classe $\mathrm{PH} 3 \mathrm{E}$, com promoção horizontal de mais $10 \%$ para compor a remuneração.

Concretamente, nos 20 anos de trabalho do professor da rede municipal de ensino de Campo Grande, o PCRR municipal, em termos de reajustes, foi importante ao se levarem em conta as promoções horizontais e verticais em sua carreira. Aplicam-se também outros $15 \%$ do adicional por tempo de serviço ${ }^{6}$. Ao se cotejarem seus holerites com o PCCR, apurou-se que a concepção de valorização posta no âmbito jurídico-legal, em parte, efetivou-se nas condições materiais de existência desse professor. Cabe pontuar que os mecanismos de indução dessa valorização profissional por meio da remuneração deram-se por reajustes, tendo, exclusivamente, como parâmetro o PCCR municipal. Assim foram fundamentais, para o professor em questão, a titulação e o tempo de trabalho.

A materialidade da valorização realizou-se, em parte, porque o período de trabalho do professor foi entrecruzado também pela instituição nacional do PSPN, que se deu em 2008 (BRASIL, 2008a), mas que, de fato, só começou a valer em 2011. Ainda assim, o professor municipal não recebeu o $\mathrm{PSPN}^{7}$ na integralidade em 2016, como já mencionado. O contexto de valorização profissional por meio da remuneração do professor deve-se, em larga medida, ao grau de organicidade que os docentes conseguiram construir, fazendo-se representar por meio de sua organização sindical, que mantém afiliação nacional.

Outro cenário relativo à valorização profissional, por meio da remuneração do professor em questão, foi auferido na comparação entre o seu vencimento base no cargo e o salário mínimo. Certamente, "o salário mínimo é uma referência político-institucional que, em tese, assegura o mínimo de subsistência para o trabalhador e sua família" (FERNANDES; GOUVEIA; BENINI, 2012, p. 344). De 2002 a 2015, "a política de recuperação de seu valor significa a atualidade dessa ideia” (FERNANDES; GOUVEIA; BENINI, 2012, p. 344) em relação ao salário mínimo. Por isso mesmo, a defesa do salário mínimo sempre esteve

\footnotetext{
6 De acordo com os dispositivos da Lei n 5.565, de 23 de junho de 2015 (CAMPO GRANDE, 2015).

7 No município de Campo Grande, o PSPN foi implantado a partir de 2011. Foi implantando enquanto piso para o pagamento do professor formado em nível médio, com jornada de trabalho de quarenta horas semanais, como dispôs a Lei n 11.738/2008 (BRASIL, 2008a). Para os professores formados em nível superior, o PSPN deveria incidir na carreira perante o PCCR implantando. Como isso não vem ocorrendo de forma integral, isto é, para aquele professor formado em nível superior, tanto o reajuste do PSPN quanto do PCCR, ainda não alcançaram os mesmos índices de reajuste que o dos professores formados em nível médio. Os professores com essa formação até 2016 não recebiam o PSPN na integralidade, somente os formados em nível médio (CAMPO GRANDE, 2012).
} 
presente na pauta reivindicatória do movimento sindical docente "como referência para auferir perdas e ganhos, tanto em relação à carreira quanto em termos remuneratórios" (CONFEDERAÇÃO NACIONAL DOS TRABALHADORES EM EDUCAÇÃO, 2014, p. 73).

A Tabela 2 traz o valor do salário mínimo, o vencimento base no cargo e a remuneração do professor da rede municipal de ensino em termos de quantidades do salário mínimo no período em tela, com o objetivo de examinar se houve valorização dos ganhos do professor em relação ao salário mínimo.

Tabela 2 - Município de Campo Grande: comparativo do salário mínimo com o vencimento base no cargo e o total da remuneração de um professor em valores correntes, 1996-2016

$R \$ 1,00$

\begin{tabular}{lccc}
\hline Ano & Salário Mínimo & $\begin{array}{c}\text { Vencimento base } \\
\text { no cargo }\end{array}$ & $\begin{array}{c}\text { Total da } \\
\text { remuneração }\end{array}$ \\
\hline 1996 & 112,00 & 1,58 s.m. & 2,45 s.m. \\
1998 & 130,00 & 1,48 s.m. & 2,87 s.m. \\
2002 & 200,00 & 1,45 s.m. & 2,70 s.m. \\
2004 & 260,00 & 1,94 s.m. & 3,14 s.m. \\
2008 & 415,00 & 2,61 s.m. & 3,86 s.m. \\
2014 & 724,00 & 4,93 s.m. & 5,86 s.m. \\
2016 & 880,00 & 4,55 s.m. & 5,63 s.m. \\
\hline
\end{tabular}

s.m.: salário mínimo.

Fonte: Elaboração própria (2018) a partir das Leis $n^{\circ} 9.971 / 2000, n^{\circ} 11.709 / 2008 c ; M P$ $n^{\circ} 35 / 2002, n^{\circ} 182 / 2004$ e Decretos no 8.166/2013, n 8.618/2015

Ao se tomar o salário mínimo como base 100 em 1996, com o valor de $\mathrm{R} \$ 112,00$, observou-se que, em 1996, o valor do vencimento base no cargo do professor correspondia a 1,58 salário mínimo e a 2,45 salários mínimos no total da remuneração com a formação em nível médio. Nos 20 anos verificados, o quantitativo de salários mínimos aumentou para 4,55 no vencimento base e 5,63 em relação ao total da remuneração, movimento esse que pode ter sido proporcionado pelos percentuais do PCRR, devido às promoções horizontais e verticais e pelos adicionais por tempo de serviço.

A queda do vencimento base no cargo e da remuneração, na comparação com o quantitativo de salários mínimos, ocorreu de 2014 para 2016, de acordo 
com a Tabela 2, dados os reajustes remuneratórios e a integralização do PSPN por 20 horas de jornada de trabalho, dispositivos da Lei $\mathrm{n}^{\circ} 5.411 / 2014$ (CAMPO GRANDE, 2014), mas que não foram pagos pelo executivo municipal. Não obstante a categoria laboral ter respondido a essa situação com uma greve, o movimento grevista foi insuficiente, naquela conjuntura, para garantir a materialidade dos dispositivos da Lei, mesmo após aprovação pelo Poder Legislativo.

\title{
4 Considerações Finais
}

O trabalho objetivou, a partir de um estudo de caso, ao cotejar os holerites de um professor da educação básica da rede municipal de ensino de Campo Grande, com os PCCR aprovados em um período de 20 anos, verificar qual efeito seria provocado nas condições materiais de existência desse professor, tanto no que concerne ao vencimento base no cargo, quanto à sua remuneração.

Com efeito, no período em tela,

\begin{abstract}
diversas políticas vêm sendo implementadas para aumentar o salário dos professores, com ênfase no aumento do piso salarial, implementado em 2009, e na promoção de sistemas de carreira previstos, entre outros, na lei que estabelece o Plano Nacional de Educação (PNE) (HIRATA; OLIVEIRA; MEREB, 2019, p. 191).
\end{abstract}

Observou-se que, em sistemas descentralizados de ensino em contexto federativo, houve interseção entre as políticas locais com vistas à valorização profissional com as de âmbito federal, em termos de concepção.

Nesse caso em particular, a indução feita pelo governo federal provocou alterações no escopo jurídico-legal local, que remeteu principalmente à implantação de PCCR, o que fomentou de forma positiva a carreira docente em esfera municipal.

Ainda que o Fundeb possa ser considerado como uma política de coordenação federativa, não resolveu as assimetrias regionais por meio do financiamento da educação. Certamente, a questão do financiamento da educação ainda é um daqueles "obstáculos econômicos" por onde manifesta-se "a histórica resistência à manutenção da educação pública no Brasil”" (SAVIANI, 2009, p. 22). 
Nesse sentido, na análise da situação do professor em questão, constatou-se um efeito positivo no movimento da carreira em 20 anos, ao se considerar sua titulação e tempo de trabalho.

Ainda assim, permaneceu no horizonte futuro do professor, o pagamento integral do PSPN, dispositivo da Lei ${ }^{\circ} 11.738 / 2008$ (BRASIL, 2008a). Como a metáfora anunciada por Fiori (2003), a valorização do professor por meio remuneratório tem-se constituído, via de regra, como uma "fuga para a frente" (FIORI, 2003, p. 185).

A valorização profissional docente, por meio da remuneração para garantir mínimas condições materiais de existência, foi dada, no período, em termos de concepção jurídico-legal. Sua materialidade, em parte realizada e, em parte, não, continuou no devir histórico.

Esse foi um momento de possibilidades de valorização docente que se encerrou. A conjuntura que se estabeleceu a partir de 2016 com o golpe legislativojudiciário-midiático (AMARAL, 2017) deu início a uma série de contrarreformas que, definitivamente, terão implicações severas no panorama de valorização dos professores da educação básica. Entre essas contrarreformas, estão a Emenda à Constituição Federal $n^{\circ}$ 95/2016, a Reforma Trabalhista instituída pela Lei $\mathrm{n}^{\mathrm{o}}$ 13.467/2017 e a Lei n ${ }^{\mathrm{o}}$ 13.415/2017 (BRASIL, 2016, 2017a, 2017b). Certamente, a contrarreforma em curso provocará efeitos ainda não mensuráveis, mas que contradizem todo o escopo jurídico-legal construído até então, bem como a luta do magistério pela sua valorização. 


\section{Teachers' remuneration: the effects of the work position, carrer and remuneration planimplemented in a municipality}

\section{Abstract}

The objective of the paper was, by means of a case study, to check the effect produced by the Work Position, Career and Remuneration Plans (Planos de Cargos, Carreira e Remuneração, PCCR) implemented in the municipality of Campo Grande from 1996 to 2016, regarding the remuneration paid to a teacher during 20 years of work. The change in teacher's remuneration was obtained with the analysis of their pay slips, in relation to the PCCR and the minimum wage. There was a positive effect on the teacher's remuneration, due to the obligation of the municipal PCCR. Their diplomas and years of work were important in terms of valuing the teacher's activity. However, the integral remuneration of the PSPN (National Professional Salary Floor), which should also be ensured by means of the PCCR, is yet to be accomplished in that municipality.

Keywords: Education Policy. PCCR. Teachers'Remuneration. Teachers'Valuation.

\section{Remuneración docente: efectos de los estatutos de cargos, carrera y remuneración en el contexto municipal}

\section{Resumen}

El trabajo se propone, por medio del estudio de caso, verificar el efecto producido por los Planes de Cargos, Carrera y Remuneración (PCCR) implementados en la ciudad de Campo Grande en el período de 1996 a 2016, en términos de remuneración salarial para un profesor, en el transcurso de 20 años de carrera. El examen del movimiento de la remuneración del profesor fue realizado mediante el análisis de sus recibos de sueldo, en comparación con el PCCR y el sueldo mínimo. Se constató que hubo un efecto positivo en la remuneración del profesor con la obligatoriedad de los PCCR municipales y que la titulación, así como el tiempo de trabajo fueron importantes en el contexto de la valorización profesional. Permaneció, entretanto, la promesa histórica en el municipio, del pago integral del PSPN (Piso salarial profesional nacional), que también debería estar garantizado por intermedio del PCCR.

Palabras clave: Política Educacional. PCCR. Remuneración del Profesor. Valorización del Profesor. 


\section{Referências}

AMARAL, N. C. O "novo" ensino médio e o PNE: haverá recursos para essa política? Revista Retratos da Escola, Brasília, DF, v. 11, n. 20, p. 91-108, 2017. https://doi.org/10.22420/rde.v11i20.759

BRASIL. Constituição (1988). Constituição da República Federativa do Brasil. Brasília, DF: Senado Federal, 1988.

BRASIL. Decreto $\mathrm{n}^{\circ}$ 8.166, de 23 de dezembro de 2013. Regulamenta a Lei $\mathrm{n}^{\mathrm{o}} 12.382$, de 25 de fevereiro de 2011, que dispõe sobre o valor do salário mínimo e a sua política de valorização de longo prazo. Diário Oficial da União, Brasília, DF, 24 dez. 2013.

BRASIL. Decreto $\mathrm{n}^{\mathrm{o}}$ 8.618, de 29 de dezembro de 2015. Regulamenta a Lei $\mathrm{n}$. 13.152, de 29 de julho de 2015, que dispõe sobre o valor do salário mínimo e a sua política de valorização de longo prazo. Diário Oficial da União, Brasília, DF, 30 dez. 2015.

BRASIL. Emenda Constitucional no 14, de 12 de setembro de 1996. Modifica os arts. 34, 208, 211 e 212 da Constituição Federal e dá nova redação ao art. 60 do Ato das Disposições constitucionais transitórias. Diário Oficial da União, Brasília, DF, 13 set. 1996c.

BRASIL. Emenda Constitucional no 95, de 15 de dezembro de 2016. Altera o Ato das Disposições Constitucionais Transitórias, para instituir o Novo Regime Fiscal, e dá outras providências. Diário Oficial da União, Brasília, DF, 15 dez. 2016.

BRASIL. Lei no 9.394, de 20 de dezembro de 1996. Estabelece as diretrizes e bases da educação nacional. Diário Oficial da União, Brasília, DF, 23 dez. 1996a.

BRASIL. Lei $\mathrm{n}^{\circ}$ 9.424, de 24 de dezembro de 1996. Dispõe sobre o Fundo de Manutenção e Desenvolvimento do Ensino Fundamental e de Valorização do Magistério na forma prevista no art. 60 do ADCT e dá outras providências. Diário Oficial da União, Brasília, DF, 26 dez. 1996b.

BRASIL. Lei n ${ }^{\circ}$ 9.971, de 18 de maio de 2000. Dispõe sobre o salário mínimo a partir de $1^{\circ}$ de maio de 1996 e dá outras providências. Diário Oficial da União, Brasília, DF, 19 maio 2000. 
BRASIL. Lei $\mathrm{n}^{\circ}$ 10.172, de 9 de janeiro de 2001. Aprova o Plano Nacional de Educação e dá outras providências. Diário Oficial da União, Brasília, DF, 10 jan. 2001.

BRASIL. Lei no 11.494 , de 20 de junho de 2007. Regulamenta o Fundo de Manutenção e Desenvolvimento da Educação Básica e de Valorização dos Profissionais da Educação - FUNDEB, de que trata o art. 60 do Ato das Disposições Constitucionais Transitórias; altera a Lei ${ }^{\circ} 10.195$, de 14 de fevereiro de 2001; revoga dispositivos das Leis n. ${ }^{\circ}$ 9.424, de 24 de dezembro de 1996, 10.880, de 9 de junho de 2004, e 10.845, de 5 de março de 2004; e dá outras providências. Diário Oficial da União, Brasília, DF, 22 jun. 2007.

BRASIL. Lei no 11.709 , de 20 de junho de 2008. Dispõe sobre o salário mínimo a partir de $1^{\circ}$ de março de 2008 e dá outras providências. Diário Oficial da União, Brasília, DF, 20 jun. 2008c.

BRASIL. Lei no 11.738, de 16 de julho de 2008. Regulamenta a alínea "e" do inciso III do caput do art. 60 do Ato das Disposições Constitucionais Transitórias, para instituir o piso salarial profissional nacional para os profissionais do magistério público da educação básica. Diário Oficial da União, Brasília, DF, 17 jul. 2008a.

BRASIL. Lei $\mathrm{n}^{\circ} 12.527$, de 18 de novembro de 2011. Regula o acesso a informações previsto no inciso XXXIII do art. 5o, no inciso II do § 30 do art. 37 e no $\S 20$ do art. 216 da Constituição Federal; altera a Lei ${ }^{\circ} 8.112$, de 11 de dezembro de 1990; revoga a Lei $\mathrm{n}^{\circ} 11.111$, de 5 de maio de 2005, e dispositivos da Lei $\mathrm{n}^{\circ} 8.159$, de 8 de janeiro de 1991; e dá outras providências. Diário Oficial da União, Brasília, DF, 18 nov. 2011.

BRASIL. Lei $\mathrm{n}^{\mathrm{o}} 13.005$, de 25 de junho de 2014. Aprova o Plano Nacional de Educação - PNE e dá outras providências. Diário Oficial da União, Brasília, DF, 26 jun. 2014b.

BRASIL. Lei $\mathrm{n}^{\mathrm{o}} 13.415$, de 16 de fevereiro de 2017. Altera as Leis $\mathrm{n}^{\text {os }}$ 9.394, de 20 de dezembro de 1996, que estabelece as diretrizes e bases da educação nacional, e 11.494, de 20 de junho 2007, que regulamenta o Fundo de Manutenção e Desenvolvimento da Educação Básica e de Valorização dos Profissionais da Educação, a Consolidação das Leis do Trabalho - CLT, aprovada pelo Decreto-Lei $\mathrm{n}^{\circ} 5.452$, de $1^{\circ}$ de maio de 1943, e o Decreto-Lei $\mathrm{n}^{\mathrm{o}}$ 236, de 28 de fevereiro de 1967; revoga a Lei $\mathrm{n}^{\mathrm{o}} 11.161$, de 5 de agosto de 2005; e institui a Política de Fomento à Implementação de Escolas de Ensino Médio em Tempo Integral. Diário Oficial da União, Brasília, DF, 17 fev. 2017b. 
BRASIL. Lei n ${ }^{\circ}$ 13.467, de 13 de julho de 2017. Altera a Consolidação das Leis do Trabalho (CLT), aprovada pelo Decreto-Lei ${ }^{\circ} 5.452$, de 1 o de maio de 1943, e as Leis $\mathrm{n}^{\text {os }} 6.019$, de 3 de janeiro de 1974, 8.036, de 11 de maio de 1990, e 8.212, de 24 de julho de 1991, a fim de adequar a legislação às novas relações de trabalho. Diário Oficial da União, Brasília, DF, 14 jul. 2017a.

BRASIL. Lei Complementar $n^{\circ} 131$, de 27 de maio de 2009. Acrescenta dispositivos à Lei Complementar n. 101, de 4 de maio de 2000, que estabelece normas de finanças públicas voltadas para a responsabilidade na gestão fiscal e dá outras providências, a fim de determinar a disponibilização, em tempo real, de informações pormenorizadas sobre a execução orçamentária e financeira da União, dos Estados, do Distrito Federal e dos Municípios. Diário Oficial da União, 28 maio 2009.

BRASIL. Medida Provisória ${ }^{\circ}$ 35, de 28 de março de 2002. Dispõe sobre o salário mínimo a partir de $1^{\circ}$ de maio de 2002 e dá outras providências. Diário Oficial da União, Brasília, DF, 28 mar. 2002.

BRASIL. Medida Provisória $n^{0} 182$, de 29 de abril de 2004. Dispõe sobre o salário mínimo a partir de $1^{\circ}$ de maio de2004 e dá outras providências. Diário Oficial da União, Brasília, DF, 30 abr. 2004.

BRASIL. Ministério da Educação. Conferência Nacional da Educação Básica: documento final. Brasília, DF: 2008b.

BRASIL. Ministério da Educação. Conferência Nacional de Educação 2010: documento final. Brasília, DF: 2010.

BRASIL. Ministério da Educação. Conferência Nacional de Educação 2014: documento final. Brasília, DF: 2014a.

CAMARGO, R. B. et al. Financiamento da educação e remuneração docente: um começo de conversa em tempos de piso salarial. Revista Brasileira de Política e Administração da Educação, Goiânia, v. 25, n. 2, p. 341-363, maio/ ago. 2009. https://doi.org/10.1573/vol25n22009.19501

CAMPO GRANDE. Decreto $n^{\circ} 10.343$, de 22 de janeiro de 2008. Publica e Consolida a Lei Complementar n. 19, institui o PCRM, com alterações e inclusões das Leis Complementares n. 20, n. 97 e 106. Campo Grande, 2008a. Disponível em: http://www.tce.ms.gov.br/ccivil_03/.htm. Acesso em: 18 mar. 2015. 
CAMPO GRANDE. Lei $n^{\circ}$ 5.060, de 3 de abril de 2012. Dispõe sobre a revisão geral de remuneração dos servidores do poder executivo, e dá outras providências. Campo Grande, 2012. Disponível em: http://www.camara. ms.gov.br/legislacao-municipal Acesso em: 3 de maio 2018.

CAMPO GRANDE. Lei $n^{\circ} 5.189$, de 24 de maio de 2013. Dispõe sobre a revisão geral da remuneração dos servidores do poder executivo, e dá outras providências. Diogrande, Campo Grande, 27 maio 2013.

CAMPO GRANDE. Lei $n^{\circ} 5.411$, de 4 de dezembro de 2014. Altera a lei $n$. 5.189/2013, que dispõe sobre a revisão geral da remuneração dos servidores do poder executivo. Campo Grande, 2014a. Disponível em: http://campogrande. ms.gov.br/leisweb/index.pdf . Acesso em 22 fev. 2017.

CAMPO GRANDE. Lei $n^{\circ} 5.565$, de 23 de junho de 2015. Aprova o Plano Municipal de Educação do Município de Campo Grande - MS e dá outras providências. Campo Grande, 2015. Disponível em: http://www.campogrande. ms.gov.br/cme/downloads/plano-municipal-de-educacao-campo-grandemspme-2015-2025/. Acesso em: 20 abr. 2018.

CAMPO GRANDE. Lei complementar $n^{\circ} 19$, de 15 de julho de 1998. Dispõe sobre o Plano de Carreiras e Remuneração do Magistério de Campo Grande. Campo Grande, 1998a. Disponível em http://www.pmcg.ms.gov.br/leisweb/ index.19de\%191998.pdf Acesso em: 15 maio 2017.

CAMPO GRANDE. Prefeitura Municipal. Demonstrativo de Pagamento ServidorMunicipal. Campo Grande, 1996.

CAMPO GRANDE. Prefeitura Municipal. Demonstrativo de Pagamento Servidor Municipal. Campo Grande, 1998c.

CAMPO GRANDE. Prefeitura Municipal. Demonstrativo de Pagamento Servidor Municipal. Campo Grande, 2002.

CAMPO GRANDE. Prefeitura Municipal. Demonstrativo de Pagamento Servidor Municipal. Campo Grande, 2004.

CAMPO GRANDE. Prefeitura Municipal. Demonstrativo de Pagamento Servidor Municipal. Campo Grande, 2008b.

CAMPO GRANDE. Prefeitura Municipal. Demonstrativo de Pagamento Servidor Municipal. Campo Grande, 2014b. 
CAMPO GRANDE. Prefeitura Municipal. Demonstrativo de Pagamento Servidor Municipal. Campo Grande, 2016.

CAMPO GRANDE. Relatório preliminar de avaliação do Plano Municipal de Educação - PME de Campo Grande-MS Lei Municipal n ${ }^{\circ} 5.565$ de 23 de junho de 2015 Período 2016-2017. Campo Grande, 2018. Disponível em: http://www.campogrande.ms.gov.br/pme/wp-content/uploads/sites/54/2018/03/ Relat\%C3\%B3rio-de-Avalia\%C3\%A7\%C3\%A3o-PME-CG-2016-2017.pdf. Acesso em: 27 maio 2018.

\section{CONFEDERAÇÃO NACIONAL DOS TRABALHADORES EM} EDUCAÇÃO. Cadernos de Resoluções. Brasília, DF: 2014. Disponível em: http://www.cnte.org.br/images/stories/2014/caderno_de_resolucoes_2014.pdf. Acesso em: 01 maio 2018.

DA MATA, F. Por 23 votos a 6, prefeito de Campo Grande é cassado pela Câmara. G1 Mato Grosso do Sul TV Morena, Campo Grande, 2104. Disponível em: http:// g1.globo.com/mato-grosso-do-sul/noticia/2014/03/por-23-votos-6-prefeito-decampo-grande-e-cassado-pela-camara.html. Acesso em: 20 abr. 2018.

DOURADO, L. F. Plano Nacional de Educação: o epicentro das políticas de estado para a educação brasileira. Goiânia: Imprensa Universitária, 2017.

FERNANDES, M. D. E.; RODRIGUEZ, M. V. O processo de elaboração da lei n ${ }^{\circ}$ 11.738/2008 (lei do piso salarial profissional nacional para carreira e remuneração docente): trajetória, disputas e tensões. Revista HISTEDBR On-Line, [s. l.], v. 11, n. 41, p. 88-101, mar. 2011. https://doi.org/10.20396/rho.v11i41.8639837

FERNANDES, M. D. E; GOUVEIA, A. B; BENINI, E. G. Remuneração de professores no Brasil: um olhar a partir da Relação Anual de Informações Sociais (RAIS). Educação e Pesquisa, São Paulo, v. 38, n. 2, p. 339-356, jun. 2012. https://doi.org/10.1590/S1517-97022012000200005

FERNANDES, M. D. E. et al. Remuneração de professores de educação básica nos setores público e privado na esfera municipal. Educação e Pesquisa [online], São Paulo, v. 44, e161233, 2018. [citado em 29 ago. 2019]. Disponível em: http://www.scielo.br/scielo.php?script=sci arttext\&pid=S1517-97022018000100412\&lng=en\&nrm=iso\&tlng $=$ pt\&ORIG INALLANG=pt.Epub 27 jul. 2017. ISSN 1517-9702.https://doi.org/10.1590/ s1678-4634201706161233

FIORI, J. L. O vôo da coruja: pare reler o desenvolvimentismo brasileiro. Rio de Janeiro: Record, 2003. 
GOUVEIA, A. B. Avaliação da política educacional municipal: em busca de indicadores de efetividade nos âmbitos do acesso, gestão e financiamento. Ensaio: Avaliação e Políticas Públicas em Educação, Rio de Janeiro, v. 17, n. 64, p. 449476, jul./set. 2009. https://doi.org/10.1590/S0104-40362009000300004

HIRATA, G.; OLIVEIRA, J. B. A.; MEREB, T. M. Professores: quem são, onde trabalham, quanto ganham. Ensaio: Avaliação e Políticas Públicas em Educação, Rio de Janeiro, v. 27, n. 102, p. 179-203, mar. 2019. https://doi. org/10.1590/s010440362018002701888

MORDUCHOWICZ, A. Carreiras, incentivos e estruturas salariais docentes. Preal Brasil, Rio de Janeiro, n. 23, p. 1-60, 2003.

SAVIANI, D. Sistema de educação: subsídios para a Conferência Nacional de Educação. Brasília, DF: Ministério da Educação, 2009. Disponível em: conae.mec. gov.br/images/stories/pdf/conae_dermevalsaviani.pdf. Acesso em: 27 maio 2019.

SINDICATO CAMPO-GRANDENSE DOS PROFISSIONAIS DA EDUCAÇÃO PÚBLICA. - ACP. Tabela salarial. Campo Grande, 2017. Disponível em: http:// www.acpms.com.br/tabela-de-salarios. Acesso em: 20 abr. 2018.

VALENTE, I. Plano Nacional de Educação. Rio de Janeiro: DP\&A, 2001.

VALLE, B. B. R. Salário do professor: da posse à aposentadoria. Revista da $A N D E$, n. 4, p. 26-42, 1982.

\section{Informações das autoras}

Maria Dilnéia Espíndola Fernandes: Doutora em Educação pela Universidade Estadual de Campinas. Professora titular do Programa de Pós-Graduação em Educação da Universidade Federal de Mato Grosso do Sul. Bolsista produtividade em pesquisa do Conselho Nacional de Desenvolvimento Científico e Tecnológico. Contato: mdilneia@gmail.com

iD http://orcid.org/0000-0001-5218-8541

Solange Jarcem Fernandes: Doutora em Educação pela Universidade Federal de Mato Grosso do Sul. Professora adjunta do Programa de Pós-Graduação em Educação da mesma Universidade. Contato: solangejarcem@gmail.com

(iD) http://orcid.org/0000-0003-0287-6172

Viviane Gregorio de Campo: Professora municipal da Educação Básica. Contato: vivigreg@terra.com.br

iD http://orcid.org/0000-0002-7950-5057 